\title{
Proximate and ultimate causes: how come? and what for?
}

\section{Citation}

Haig, David. 2013. "Proximate and Ultimate Causes: How Come? and What For?" Biol Philos 28 (5) (April 3): 781-786. doi:10.1007/s10539-013-9369-z.

\section{Published Version}

doi:10.1007/s10539-013-9369-z

\section{Permanent link}

http://nrs.harvard.edu/urn-3:HUL.InstRepos:23931958

\section{Terms of Use}

This article was downloaded from Harvard University's DASH repository, and is made available under the terms and conditions applicable to Open Access Policy Articles, as set forth at http:// nrs.harvard.edu/urn-3:HUL.InstRepos:dash.current.terms-of-use\#OAP

\section{Share Your Story}

The Harvard community has made this article openly available.

Please share how this access benefits you. Submit a story.

Accessibility 


\title{
Proximate and ultimate causes: How come? and What for?
}

\author{
David Haig \\ Department of Organismic and Evolutionary Biology, \\ Harvard University, 26 Oxford Street, \\ Cambridge MA 02138.
}

\begin{abstract}
Proximate and ultimate causes in evolutionary biology have come to conflate two distinctions. The first is a distinction between immediate and historical causes. The second is between explanations of mechanism and adaptive function. Mayr emphasized the first distinction but many evolutionary biologists use proximate and ultimate causes to refer to the second. I recommend that 'ultimate cause' be abandoned as ambiguous.
\end{abstract}

Keywords: proximate cause; ultimate cause; efficient cause; final cause; intentionality; adaptation; natural selection

The proximate/ultimate distinction in biology is commonly, although not universally, viewed as a distinction between explanations of mechanism and explanations of adaptive function. The distinction is usually accredited to Mayr (1961) although his intended distinction was between explanations in terms of immediate causes and in terms of evolutionary history. Recent debates about whether the distinction is useful, outdated, or pernicious have involved much arguing at cross-purposes with the protagonists meaning different things by 'ultimate cause.' Two criteria are often invoked to determine the 'correct' definition of a term. One is historical: what did Mayr mean by ultimate cause? The other is majoritarian: what do most individuals in community $x$ mean by ultimate cause? Mayr's (1961) prose is not particularly clear, but I will suggest some critics of Mayr's distinction employ a definition closer to Mayr's intended meaning than do most of his supporters. 


\section{Ernst Mayr and proximate and ultimate causes.}

When we say "why" we must always be aware of the ambiguity of this term. It may mean "how come?," but it may also mean the finalistic "what for?" It is obvious that the evolutionary biologist has in mind the historical "how come?" when he asks "why?" (Mayr 1961)

Cause and effect in biology was presented to the Hayden Colloquium on Scientific Method and Concept at MIT during the academic year 1960-1961 (Lerner 1965; Beatty 1994). A version was published in Science (Mayr 1961) and subsequently in the proceedings of the Hayden Colloquium (Mayr 1965). The two versions are highly similar but not identical.

One must consider Mayr's 'political' motivations to understand the goals of Cause and effect in biology. An important motivation was to defend the place of systematics and evolutionary biology in the academy against triumphalist molecular biology (Beatty 1994; Dietrich 1998), whilst at the same time disowning connection between evolutionary biology, correctly delimited, and various vitalistic theories. The criticisms against which Mayr wished to defend his discipline are not difficult to divine, both from his text and because evolutionary biologists, 50 years later, still encounter the same criticisms. Evolutionary biology, it is said, smuggles in unscientific, teleological concepts and is less rigorous and predictive than the 'hard' sciences.

Mayr (1961, 1965) structured his paper around three aspects of causality: explanation of past events, prediction of future events, and teleology. He first distinguished two broad disciplines, functional and evolutionary biology, with different explanatory goals and different causal concepts. Mayr identified the functional biologist's question as "How?" and the evolutionary biologist's question as "Why?" where the latter was understood as the historical "How come?" rather than the finalistic "What for?" The functional biologist was concerned with immediate causes whereas the evolutionary biologist was concerned with "causes that have a history." Thus, "proximate causes govern the responses of the individual (and his organs) to immediate factors of the environment, while ultimate causes are responsible for the evolution of the particular DNA code of information with which every individual of every species is endowed." 
Mayr's treatment of teleology is revealing. He explictly disavows "What for?" because of its teleological overtones. Goal-directed behaviors are present in biology but these are caused by the playing out of evolved genetic programs. By implication, how these programs are expressed is the province of functional biologists, but the non-teleological origin of these programs is the realm of evolutionary biologists. "The development or behavior of an individual is purposive, natural selection is definitely not." Mayr subtly shifts the stigma of teleological (or teleonomic) thinking from evolutionary to functional biology.

What did Mayr mean by proximate and ultimate causes and why did he choose these terms? More than once, Mayr states that proximate causes are immediate whereas ultimate causes are historical. Therefore, ultimate causes are presented as temporally prior to proximate causes. Mayr clearly did not believe that evolutionary causes were without prior cause, so why choose 'ultimate' rather than, say, 'remote'? This is politics. Proximate causes are more salient than remote causes, but ultimate valorizes the evolutionary over the merely proximate.

\section{Proximate and ultimate causes after Mayr}

Mayr's proximate/ultimate distinction has been widely adopted by evolutionary biologists, but largely ignored by functional biologists. Perhaps, some of the attraction to evolutionary biologists has been the invidious comparison between ultimate and proximate. But the connotation, that ultimate causes are more important than proximate causes, will certainly not have endeared the distinction to functional biologists. 'Ultimate cause' has been labeled "simply pretentious" (Francis 1990) and "disciplinary chauvinism" (Dewsbury 1991).

The ambiguity of 'Why?' created ambiguity in the meaning of ultimate causes. Mayr explicitly disavowed the finalistic 'What for?' in favor of the historical 'How come?' but for many evolutionary biologists it is 'What for?' that distinguishes ultimate from proximate explanations. 'What for?' is exclusively concerned with natural selection, but 'How come?' encompasses additional historical factors. Tinbergen (1968) avoided the ambiguity of 'Why?' by separating questions of survival value from evolutionary history.

Close attention to whether authors ask 'How come?' or 'What for?' clarifies their positions and illuminates causes of misunderstanding in current debates 
about proximate and ultimate causes. Some see the relevant distinction as predominantly temporal (of immediate versus historical causes):

This conceptual dichotomy is a deeply engrained habit of thinking and is characterized by the belief that aspects of development are determined by either (a) events which occurred earlier in the development of the individual, or (b) preontogenetic factors which operated on the ancestors of the individual. (Lickliter \& Berry 1990)

Proximate explanations focus on causes in the present; evolutionary explanations focus on how the present has been shaped by events in the past. (Hochman 2013)

Proximate causes are immediate, mechanical influences on a trait ... ultimate causes are historical explanations ... (Laland et al. 2013)

From this perspective, the distinction between proximate and evolutionary causes is seen as a false dichotomy, without a principled distinction between 'How?' and 'How Come?' By contrast, defenders of a proximate/ ultimate distinction usually focus on the difference between 'How?' and 'What for?' and implicitly or explicitly place 'How come?' on the proximate side of the ledger:

To understand behavior ... it is vital to distinguish between the 'proximate' cause (the physiological mechanism) and the 'ultimate' cause (the evolutionary 'goal') of the behavior in question. (Burnham \& Johnson 2005)

The explanatory utility of an ultimate account is not solely in a detailed phylogeny, capturing a particular trait's ancestry and shifting phenotype over time; it is the exposure of function, of why a given trait is as it is. ... Historical accounts are not in any sense default ultimate accounts, they ... can be understood in purely proximate terms. (Dickins \& Barton 2013)

Two issues have become enmeshed. The first concerns what efficient causes are important in evolutionary change. Do developmental mechanisms play a role? Does organismal evolution alter the environment and subsequent selection? Few would dissent from an affirmative answer to either question. The problem is that some define these as proximate and others as ultimate questions. Current debate 
would be clarified by abandoning talk of 'ultimate causes' because this term has come to conflate 'What for?' and 'How come?'

The second issue concerns the role of teleological reasoning and language in evolutionary biology. From this perspective, how and why separate questions of mechanism from questions of function (or purpose). This separation is the evolutionary descendant of the venerable distinction between efficient and final causes, with final causes interpreted in a strictly Darwinian sense. Some are comfortable with Darwinized final causes but others believe they have no place in science.

Cause-talk and function-talk are not simply different vocabularies, they are incommensurable. There is no common currency in which causal and functional explanations can be cashed in. There is no common currency for proximate and ultimate causes. There are no ultimate causes. (Francis 1990)

The mechanisms behind evolutionary processes leading to novelty can be explained in the absence of ultimate (final) causes, but not in the absence of proximate (efficient) causes. (Guerrero-Bosaga 2012)

"Why is A?" has two different, if related, meanings. If we are dealing with a conscious (or programmed) agent, we may ask why the agent took action A, seeking explanation of the agent's reason for action A. Absent such an agent, "why is A?" morphs into a "how?"-question form "how does A come about?" ... Thus "why?" questions concerning natural selection actually are "how?" questions. (Watt 2013)

Debate would be clarified by explicitly discussing mechanism versus function, or efficient versus final causes, rather than the ambiguous proximate versus ultimate. Part of the problem is disagreement about what constitutes a cause. Many would restrict 'cause' to efficient causation and would deny that functional explanations are causal. Tinbergen (1968) belonged to this semantic camp. With respect to his four questions (survival value, mechanism, development, evolution), he wrote:

The first question, that of survival value, has to do with the effects of behavior; the other three are, each on a different time scale, concerned with its causes. (emphasis added) 
A distinction between 'How (incorporating how come)?' and 'What for?' remains useful. Questions of mechanism and adaptive function invite different kinds of answers. Intentional language is often the most natural way to talk about adaptations. Accusations that such language illegitimately invokes supernatural entities or conscious agents are usually no more than willful misunderstanding and petty point-scoring.

There is a sense in which there are only efficient and material causes (matter in motion), but a complete account of any evolutionary process in these terms is unattainable. All practical accounts of efficient causation need somewhere to begin, and must posit causes without stated prior causes. Formal and final causes arise as ways of explaining matter in motion because of the necessary incompleteness of explanations in terms of efficient and material causes.

Genotypes determine phenotypes (by developmental processes in an environmental context), and phenotypes determine which genes are replicated (Haig 1992). By this recursive process, the effects of genes come to have a causal role in explaining which genes are present. The ends (in the previous generation) justify the means (in the next generation). It is a disciplinary convention of functional biologists that causal accounts should start with genotypes ${ }_{n}$ to explain phenotypes $_{\mathrm{n}}$ rather than with phenotypes $\mathrm{n}_{\mathrm{n}}$ to explain genotypes $\mathrm{s}_{\mathrm{n}+1}$. Adaptationists, by contrast, often argue from phenotypes to genotypes.

The meaningless operation of efficient causes, in a process summarized as natural selection, has created a world in which things exist with meanings and purposes (Dennett 2009, 2013). 'What for?' invites an 'on average' summary of past interactions between phenotypes and genotypes in complex environments. There is nothing in this view that denies an important role for development in evolutionary processes, nor that a recursive relationship exists among genotypes, phenotypes, and environments.

I thank Thomas Dickins and Samir Okasha for comments on the manuscript.

Beatty J (1994) The proximate/ultimate distinction in the multiple careers of Ernst Mayr. Biol Philos 9:333-356.

Burnham TC, Johnson DDP (2013) The biological and evolutionary logic of human cooperation. Analyse Kritik 27:113-135.

Dennett D (2009) Darwin's "strange inversion of reasoning". Proc Natl Acad Sci USA 106:10061-10065. 
Dennett D (2013) The evolution of reasons. In: B. Bashour, HD Muller, eds Contemporary philosophical naturalism and its implications. Routedge, in press.

Dewsbury DA (1999) The proximate and the ultimate: past, present, and future. Behav Process 46:189-199.

Dickins TE, Barton RA (2013) Reciprocal causation and the proximate-ultimate distinction. Biol Philos in press.

Dietrich MR (1998) Paradox and persuasion: negotiating the place of molecular evolution within evolutionary biology. J Hist Biol 31:85-111.

Francis RC (1990) Causes, proximate and ultimate. Biol Philos 5:401-415.

Guerrero-Bosagna C (2012) Finalism in Darwinian and Lamarckian evolution: lessons from epigenetics and developmental biology. Evol Biol 39:283-300.

Haig D (1992) Genomic imprinting and the theory of parent-offspring conflict. Semin Devel Biol 3:153-160.

Hochman, A (2013) The phylogeny fallacy and the ontogeny fallacy. Biol Philos in press.

Laland KN, Odling-Smee J, Hoppitt W, Uller T (2013) More of how and why: cause and effect in biology revisited. Biol Philos in press.

Lerner D, ed (1965) Cause and effect. Free Press: New York.

Lickliter R, Berry TD (1990) The phylogeny fallacy: developmental psychology's misapplication of evolutionary theory. Devel Rev 10:348-364.

Mayr E (1961) Cause and effect in biology. Science 134:1501-1506.

Mayr E (1965) Cause and effect in biology. In: D Lerner, ed. Cause and effect. Free Press: New York. pp 33-50.

Tinbergen N (1968) On war and peace in animals and man. Science 160:14111418.

Watt WB (2013) Causal mechanisms of evolution and the capacity for niche construction. Biol Philos in press. 